\title{
Design of very low-voltages and high-performance CMOS gate-driven operational amplifier
}

\author{
Hayder Khaleel AL-Qaysi ${ }^{1}$, Musaab Mohammed Jasim², Siraj Manhal Hameed ${ }^{3}$ \\ ${ }^{1}$ Department of Electronic Engineering, College of Engineering, University of Diyala, Iraq \\ ${ }^{2,3}$ Department of Computer Engineering, College of Engineering, University of Diyala, Iraq
}

\begin{tabular}{l} 
Article Info \\
\hline Article history: \\
Received Feb 9, 2020 \\
Revised Apr 10, 2020 \\
Accepted Apr 23, 2020 \\
\hline Keywords: \\
Analog MOSFETs circuits \\
CMOS operational amplifier \\
Folded cascode technique \\
Gate-driven \\
LV power supply
\end{tabular}

LV power supply

\begin{abstract}
This paper presents the description and analysis of the design and HSPICEbased simulation results of very low-voltages (LVs) power supplies and highperformance specifications CMOS gate-driven (GD) operational amplifier (OpAmp) circuit. The very LVs CMOS GD Op-Amp circuit designed using 90nm CMOS technology parameters and the folded cascode (FC) technique employed in the differential input stage. The HSPICE simulation results demonstrate that the overall gain is $73.1 \mathrm{~dB}$, the unity gain bandwidth is $14.9 \mathrm{MHz}$, the phase margin is $61^{\circ}$, the total power dissipation is $0.91 \mathrm{~mW}$, the output voltage swing is from $-0.95 \mathrm{~V}$ to $1 \mathrm{~V}$, the common-mode rejection ratio is $84.2 \mathrm{~dB}$, the equivalent input-referred noise voltage is $50.94 \mathrm{nV} / \sqrt{\mathrm{Hz}}$ at $1 \mathrm{MHz}$, the positive slew rate is $11.37 \mathrm{~V} / \mu \mathrm{s}$, the negative slew rate is $11.39 \mathrm{~V} / \mu \mathrm{s}$, the settling time is $137 \mathrm{~ns}$, the positive power-supply rejection ratio is $74.2 \mathrm{~dB}$, and the negative power-supply rejection ratio is $80.1 \mathrm{~dB}$. The comparisons of simulation results at $\pm 1 \mathrm{~V}$ and $\pm 0.814 \mathrm{~V}$ power supplies' voltages of the very LVs CMOS GD Op-Amp circuit demonstrate that the circuit functions with perfect performance specifications, and it is suitable for many considerable applications intended for very LVs CMOS Op-Amp circuits.
\end{abstract}

Copyright $\odot 2020$ Institute of Advanced Engineering and Science. All rights reserved.

\footnotetext{
Corresponding Author:

Hayder Khaleel AL-Qaysi, Department of Electronic Engineering, College of Engineering, University of Diyala, Baqubah, Diyala, Iraq. Email: hay.kha.82@gmail.com
}

\section{INTRODUCTION}

In recent years, the growing global electronics markets' needs for portable, wearable, wireless, battery-driven, and reliable electronics in submicron and nanometer VLSI analog and mixed-signal systems have generated the desire and opened new horizons in the field of scientific researches to design very lowvoltages (LVs) power supplies and efficient low power (LP) complementary metal-oxide field-effect transistors (CMOSFETs) based analog sub-circuits [1-3]. In those systems, the threshold voltages $\left(V_{t h, n, p}\right)$ of the MOSFETs are not reducing compared to the rate at which the power supplies voltages reduction [4] and the ratio of lengths-to-widths of the down-scaled MOSFETs channels [5]. In very LVs power supplies and LP MOSFETs circuits, the minimum power supplies voltages must be equal to or greater than the $V_{t h, n, p}$ values, and this imposes an additional strict restriction on the possibility of reducing the power supplies voltages [6].

However, Digital MOSFETs circuits benefit from the use of low- $V_{t h, n, p}$ values MOSFETs and very LVs power supplies to improve their performance specifications. Whereas, the use of low- $V_{t h, n, p}$ values MOSFETs and very LVs power supplies lead to the deterioration in the performance specifications of the analog MOSFETs circuits due to the effects of gate leakage currents, short-channel lengths, and permissible noise voltages margins [4-9]. Consequently, these effects increase the complexity of designing the analog 
MOSFETs circuits, and the only solution to keep pace with the performance of the digital MOSFETs circuits is to choose suitable and simple analog MOSFETs circuits topologies with very LVs power supplies.

CMOS operational amplifier (Op-Amp) circuits with different topologies are the main building blocks that perform useful and multiple functions in the analog and mixed-signal integrated circuits (ICs) [10-13]. Consequently, the selection of suitable and simple design for very LVs power supplies and high-performance specifications CMOS Op-Amp circuits is very crucial because their performance specifications directly affect the overall performance specifications of the analog and mixed-signal ICs. The minimum and maximum input common-mode $\left(V_{\text {in (min) }}, V_{\text {in (max })}\right.$, respectively) and differential-mode range voltages in the classical CMOS gate-driven (GD) Op-Amp circuits topologies are relatively small and greatly influenced by the power supplies' voltages [14]. To overcome these shortcomings, several promising very LVs power supplies' design techniques have introduced to increase the $V_{i n(\min )}$ and $V_{i n(\max )}$ values of the very LVs power supplies and highperformance specifications CMOS Op-Amp circuits topologies. Among these design techniques, the most widely used are: parallel-connected nMOSFETs and pMOSFETs differential input pairs [15, 16], DC levelshifters MOSFETs [16-20], self-cascoded MOSFETs [17, 19], sub- $V_{t h, n, p}$ region operation MOSFETs [17, 19], dynamic $V_{t h, n, p}$ MOSFETs [19], floating-gate (FG) MOSFETs [17-21], quasi floating-gate (QFG) MOSFETs [18, 20, 22, 23], and bulk-driven (BD) MOSFETs [4, 17-19]. There are advantages and disadvantages to each of these very LVs power supplies' design techniques reported in [4, 15-19]. Conclusively, all of these design techniques aim to reduce the $V_{t h, n, p}$ values or cancel their impacts on the performance specifications of the CMOS Op-Amp circuits topologies. Consequently, allow the CMOS Op-Amp circuits topologies to operate in the very LVs power supplies range with high-performance specifications.

In this paper, the main objective is to design simple, very LVs, and folded cascode (FC) techniquebased differential input stage CMOS GD Op-Amp circuit topology capable of operating at the minimum power supplies voltages that equal the sum of three drain-source saturation voltages with high-performance specifications. Our contribution to solving this problem is by simulating and analyzing the impact of the various performance specifications of the very LVs CMOS GD Op-Amp circuit at different power supplies voltages using the HSPICE simulation program. Consequently, the results are generalized with proposals to build CMOS Op-Amp circuits that have higher performance specifications in the future. The rest of this paper is arranged as follows: The description and design performance specifications of the very LVs CMOS GD Op-Amp circuit topology are presented in Section 2. HSPICE simulation results that illustrate the obtained design performance specifications are described and analyzed in Section 3. Finally, the concluding remarks of this work and future work are drawn in Section 4.

\section{VERY LVS CMOS GD OP-AMP DESCRIPTION}

The selected very LVs CMOS GD Op-Amp circuit topology in this paper is shown in Figure 1 [24]. This circuit bases on the folded cascode (FC) technique in the differential input stage. The differential input stage is composed of the simple differential GD nMOSFETs pair M1 and M2 with transistors M3 and M4, which acting as balanced-active current source pMOSFETs loads. Consequently, the use of this structure in the differential input stage has a great advantage as it provides the broadest values for the input commonmode range voltages $\left(V_{i n(\min )}\right.$ and $V_{i n(\max )}$, respectively) without the need to increase the complexity of the circuit by using the parallel-connected nMOSFETs and pMOSFETs differential input stages structure. The differential input stage is more susceptible than the other very LVs CMOS GD Op-Amp circuit stages to the impact of the very LV power supply, which its minimum value is determined by using (1):

$$
V_{D D(\min )}=V_{S D 3(\text { sat })}+V_{D S 1(\text { sat })}+V_{D S 5(\text { sat })}
$$

where $V_{S D 3(s a t)}$ is the source-drain saturation voltage of transistor $\mathrm{M} 3, V_{D S 1(s a t)}$ and $V_{D S 5(s a t)}$ are the drainsource saturation voltages of transistor M1 and nMOSFET transistor M5, respectively.

If the value of positive power supply voltage $\left(V_{D D}\right)$ is greater than $V_{D D(\min )}$, then the value of $V_{i n(\min )}$ and $V_{i n(\max )}$ are determined by using (2) and (3), respectively:

$$
V_{\text {in (min) }}=V_{S S}+V_{D S 5(s a t)}+V_{G S 1}
$$

where $V_{S S}$ is the negative power supply voltage and $V_{G S 1}$ is the gate-source voltage of transistor M1. 


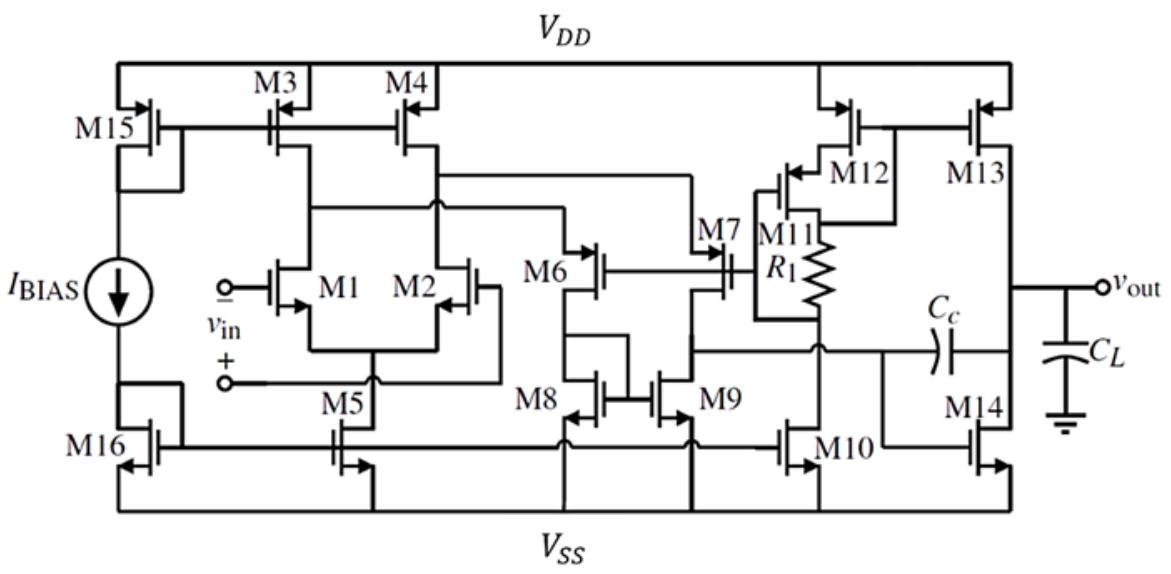

Figure 1. Topology of very LVs CMOS GD Op-Amp circuit

$$
V_{i n(\max )}=V_{D D}-V_{S D 3(s a t)}+V_{t h, n}
$$

The sources of pMOSFET transistors M6 and M7 are connected to the output of differential GD nMOSFETs pair input stage. The gate-source voltages of transistors M6 and M7 ( $V_{G S 6}$ and $V_{G S 7}$, respectively) are provided by the proper selection of the resistance value $R_{1}$. Thus, the source-drain saturation voltages of the active current source pMOSFETs loads M3 and M4 are $V_{S D 3,4(s a t)}=V_{O N}$. This provides the maximum value for the $V_{i n(\max )}$ and also allows the variation in the power supply voltage without limiting the $V_{\text {in }(\max )}$ value. The transistors M6 and M7 perform the process of folding the differential currents signals output from the differential GD nMOSFETs pair input stage, and then the nMOSFET transistors M8 and M9, which form the current-mirror circuit, convert these differential currents signals into single-ended current signals. The gain $\left(A_{v 1}\right)$ of the differential GD nMOSFETs pair input stage is determined by using (4):

$$
A_{v 1}=\frac{g_{m 1}}{g_{d s 7}+g_{d s 9}}
$$

where $g_{m 1}$ is the transconductance value of transistor M1, $g_{d s 7}$ and $g_{d s 9}$ are the channel conductance values of transistors M7 and M9, respectively.

The DC bias current source $\left(I_{B I A S}\right)$, the nMOSFET transistors M16, and the transistor M5 utilized to provide a proper Dc biasing for the very LVs CMOS GD Op-Amp circuit. To guarantee that the transistor M16 and the pMOSFET transistor M15 operating in the saturation regions, they are connected as diodes. Finally, the pMOSFET transistor M13 and the nMOSFET transistor M14 are used as a simple commonsource or class A output gain stage with Miller compensation capacitor $\left(C_{C}\right)$ technique to increase the overall gain $\left(A_{v}\right)$ and stability of the very LVs CMOS GD Op-Amp circuit. The gain $\left(A_{v 2}\right)$ of the output stage is determined by using (5):

$$
A_{v 2}=\frac{g_{m 14}}{g_{d s 13}+g_{d s 14}}
$$

where $g_{m 14}$ is the transconductance value of transistor M14, $g_{d s 13}$ and $g_{d s 14}$ are the channel conductance values of transistors M13 and M14, respectively.

Thus, the overall gain $\left(A_{v}\right)$ of the very LVs CMOS GD Op-Amp circuit is determined by using (6):

$$
A_{v}=\frac{g_{m 1} \cdot g_{m 14}}{\left(g_{d s 7}+g_{d s 9}\right) \cdot\left(g_{d s 7}+g_{d s 9}\right)}
$$

Also, the total dissipated power $\left(P_{\text {diss }}\right)$ by the very LVs CMOS GD Op-Amp circuit is determined by using (7):

$$
P_{\text {disS }}=\left(I_{B I A S}+I_{D 5}+I_{D 14}\right) \cdot\left(V_{D D}+\left|V_{S S}\right|\right)
$$

The key features of this very LVs CMOS GD Op-Amp circuit compared to the classical CMOS GD two-stage Op-Amp circuit include: 
a) It uses lower power supplies' voltages.

b) It uses balanced-active current source loads.

The desired design performance specifications of the very LVs CMOS GD Op-Amp circuit, shown in Figure 1, are listed in Table 1. The values of all MOSFETs aspect ratios $\left(W_{i} / L_{i}\right.$, where $i=1$ to 16$)$ used in this circuit are listed in Table 2, and they calculated by the utilization of design step equations developed in the reference paper [24]. Then the obtained aspect ratios' values iteratively adjusted according to the desired design performance specifications by using the HSPICE simulator program. The values of the compensation capacitor $C_{C}=2 \mathrm{pF}$, the load capacitor $C_{L}=10 \mathrm{pF}$, the resistor $R_{1}=12.3 \mathrm{~K} \Omega$, and $I_{B I A S}=20 \mu \mathrm{A}$.

Table 1. Design performance specifications of the very LVs CMOS GD Op-Amp circuit

\begin{tabular}{cc}
\hline Performance Specifications & Desired Values \\
\hline$V_{D D}(\mathrm{~V})$ & 1 \\
$V_{S S}(\mathrm{~V})$ & -1 \\
Overall Gain $\left(A_{v}\right)(\mathrm{dB})$ & $>60$ \\
Unity Gain Bandwidth $(\mathrm{GBW})(\mathrm{MHz})$ & $\geq 10$ \\
Phase Margin $(\mathrm{PM})\left({ }^{\circ}\right)$ & $\geq 60$ \\
Power Dissipation $\left(P_{\text {diss }}\right)(\mathrm{mW})$ & $\leq 1$ \\
DC Input-offset Voltage $\left(V_{O S}\right)(\mathrm{V})$ & $<0.3$ \\
Output Voltage $S$ Swing $(\mathrm{V})$ & -1 to 1 \\
CMRR $(\mathrm{dB})$ & $\geq 60$ \\
Slew Rate $(+\mathrm{ve})(\mathrm{V} / \mu \mathrm{s})$ & $\geq 10$ \\
Slew Rate $(-\mathrm{ve})(\mathrm{V} / \mu \mathrm{s})$ & $\geq-10$ \\
Settling Time $\left(T_{S}\right)(\mathrm{ns})$ & $\leq 150$ \\
$V_{\text {in }(\min )}(\mathrm{V})$ & $\geq-1$ \\
$V_{\text {in }(\max )}(\mathrm{V})$ & $\leq 1$ \\
$P S R R^{+}(\mathrm{dB})$ & $\geq 60$ \\
$P S R R^{-}(\mathrm{dB})$ & $\geq 60$ \\
Load Capacitance $\left(C_{L}\right)(\mathrm{pF})$ & $\geq 10$ \\
Resistance $\left(R_{1}\right)(\mathrm{K} \Omega)$ & $\geq 12.3$ \\
\hline
\end{tabular}

Table 2. Aspect ratios $\left(W_{i} / L_{i}\right)$ of all MOSFETs

\begin{tabular}{ccc}
\hline MOSFETs & Type & $W_{i} / L_{i}(\mu \mathrm{m} / \mu \mathrm{m})$ \\
\hline M1, M2 & nMOSFET & $3.75 / 0.5$ \\
M3, M4 & pMOSFET & $10.05 / 0.5$ \\
M5 & nMOSFET & $30 / 0.5$ \\
M6, M7, M11, M12, M15 & pMOSFET & $6.67 / 0.5$ \\
M8, M9 & nMOSFET & $0.5 / 0.5$ \\
M10, M16 & nMOSFET & $23 / 0.5$ \\
M13 & pMOSFET & $99.03 / 0.5$ \\
M14 & nMOSFET & $12.5 / 0.5$ \\
\hline
\end{tabular}

\section{SIMULATION RESULTS}

The very LVs CMOS GD Op-Amp circuit topology, shown in Figure 1, is designed and simulated by the HSPICE simulator environment using the BSIM4 model (Level 54) in 90nm CMOS technology process parameters. The simulation results of performance specifications plotted using Synopsys Cscope tools to validate the circuit design in the open-loop and unity-gain configurations. Besides, the relationships between varying the power supplies' voltages from $\pm 1 \mathrm{~V}$ to $\pm 0.814 \mathrm{~V}$ and the different performance specifications of the very LVs CMOS GD Op-Amp circuit investigated.

The design performance specifications of the very LVs CMOS GD Op-Amp circuit and the aspect ratios values of the utilized MOSFETs are listed in Tables 1 and 2, respectively, and $V_{t h, n}=0.279 \mathrm{~V}, V_{t h, p}=$ $-0.285 \mathrm{~V}, I_{B I A S}=20 \mu \mathrm{A}$. The selected channel length value of each MOSFET transistor used in the circuit is $L_{i=1 \text { to } 16}=0.5 \mu \mathrm{m}$ to minimize the effect of channel length modulation parameters $\lambda_{n}$ and $\lambda_{p}$. The HSPICE simulation results for the very LVs CMOS GD Op-Amp circuit in the open-loop configuration determine the values of the following performance specifications: overall gain $\left(A_{v}\right)$, unity gain bandwidth or gain bandwidth $(\mathrm{GBW})$, phase margin $(\mathrm{PM})$, total power dissipation $\left(P_{\text {diss }}\right)$, input resistance $\left(R_{\text {in }}\right)$, output resistance $\left(R_{\text {out }}\right)$, DC input-offset voltage $\left(V_{O S}\right)$, output voltage swing range, common-mode rejection ratio (CMRR), and equivalent input-referred noise (IRN) voltage.

Figure 2 depicts the frequency response simulation results of the circuit at $V_{D D}=\left|V_{S S}\right|=1 \mathrm{~V}$. The results show that the achieved overall gain value $\left(A_{v}\right)$ is $73.1 \mathrm{~dB}$, and the unity gain bandwidth value $(\mathrm{GBW})$ is $14.9 \mathrm{MHz}$ while the phase margin value (PM) is $61^{\circ}$. Figure 3 depicts the frequency response simulation results of the circuit at $V_{D D}=\left|V_{S S}\right|=0.814 \mathrm{~V}$. The results show that the achieved overall gain 
value $\left(A_{v}\right)$ is $71.9 \mathrm{~dB}$, and the unity gain bandwidth value $(\mathrm{GBW})$ is $14.4 \mathrm{MHz}$ while the phase margin value (PM) has not changed, and this means that the circuit has high stability.

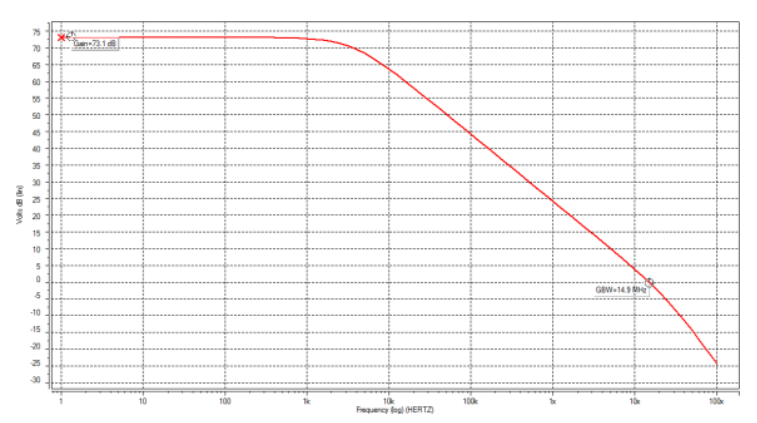

(a)

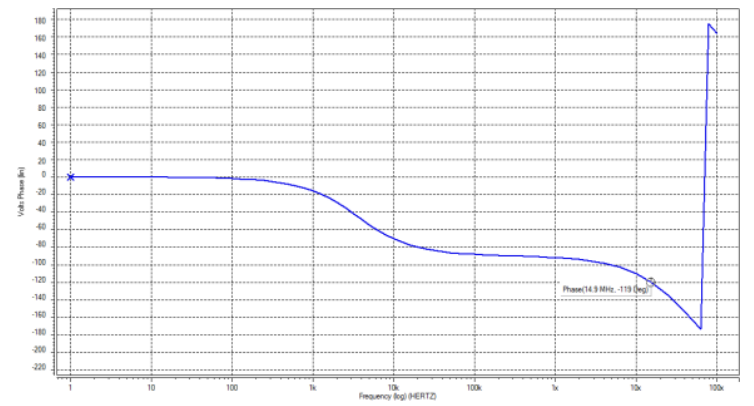

(b)

Figure 2. Frequency response of the circuit at $V_{D D}=\left|V_{S S}\right|=1 \mathrm{~V}$ (a) overall gain $\left(A_{v}\right)$. (b) phase margin (PM)

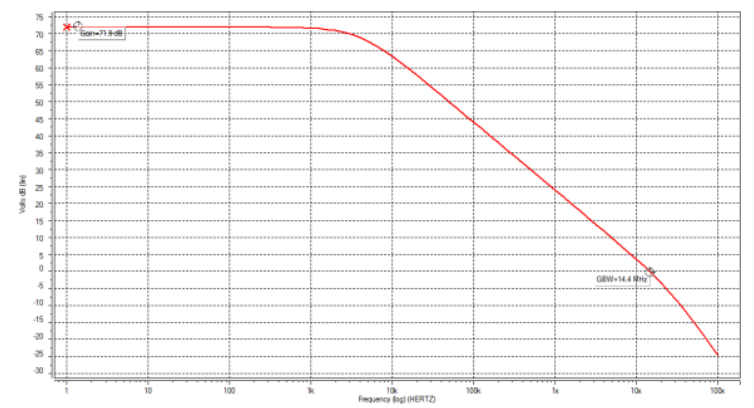

(a)

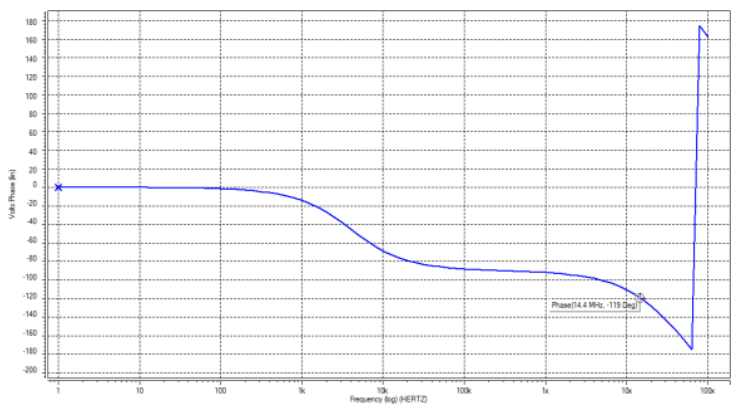

(b)

Figure 3. Frequency response of the circuit at $V_{D D}=\left|V_{S S}\right|=0.814 \mathrm{~V}$ (a) overall gain $\left(A_{v}\right)$,

(b) phase margin (PM)

The total power dissipation value $\left(P_{\text {diss }}\right)$ of the circuit at $V_{D D}=\left|V_{S S}\right|=1 \mathrm{~V}$ is $0.91 \mathrm{~mW}$ while at $V_{D D}=\left|V_{S S}\right|=0.814 \mathrm{~V}$ is found to be $0.73 \mathrm{~mW}$. The input and output resistance values $\left(R_{\text {in }}\right)$ and $\left(R_{\text {out }}\right)$ of the circuit at $V_{D D}=\left|V_{S S}\right|=1 \mathrm{~V}$ are $387 \mathrm{M} \Omega$ and $14.8 \mathrm{~K} \Omega$, respectively, while at $V_{D D}=\left|V_{S S}\right|=0.814 \mathrm{~V}$ are found to be $411 \mathrm{M} \Omega$ and $13.9 \mathrm{~K} \Omega$, respectively. Figure 4 depicts the simulation results of the DC input-offset voltage $\left(V_{O S}\right)$ and the output voltage swing of the circuit at $V_{D D}=\left|V_{S S}\right|=1 \mathrm{~V}$. The results show that the achieved DC input-offset voltage value $\left(V_{O S}\right)$ is $293 \mathrm{mV}$, while the output voltage swing range is from $-0.95 \mathrm{~V}$ to $1 \mathrm{~V}$. Figure 5 depicts the simulation results of the DC input-offset voltage $\left(V_{O S}\right)$ and the output voltage swing of the circuit at $V_{D D}=\left|V_{S S}\right|=0.814 \mathrm{~V}$. The results show that the achieved DC input-offset voltage value $\left(V_{O S}\right)$ is $0.778 \mathrm{mV}$, while the output voltage swing range is from $-0.763 \mathrm{~V}$ to $0.814 \mathrm{~V}$.

Figure 6 depicts the simulation result of the common-mode voltage gain $\left(A_{v, \mathrm{~cm}}\right)$ of the circuit at $V_{D D}=\left|V_{S S}\right|=1 \mathrm{~V}$. The result shows that the achieved common-mode voltage gain value $\left(A_{v, c m}\right)$ is $-11.1 \mathrm{~dB}$. Consequently, the common-mode rejection ratio value (CMRR) of the circuit is $84.2 \mathrm{~dB}$. This high CMRR value means that the circuit rejects perfectly the common-mode noise signals at its output. Figure 7 depicts the simulation result of the common-mode voltage gain $\left(A_{v, c m}\right)$ of the circuit at $V_{D D}=\left|V_{S S}\right|=0.814 \mathrm{~V}$. The result shows that the achieved common-mode voltage gain value $\left(A_{v, c m}\right)$ is $-11.9 \mathrm{~dB}$. Consequently, the common-mode rejection ratio value (CMRR) of the circuit is $83.8 \mathrm{~dB}$.

Figure 8 depicts the equivalent input-referred noise (IRN) voltage simulation result of the circuit at $V_{D D}=\left|V_{S S}\right|=1 \mathrm{~V}$. The result shows that the achieved equivalent input-referred noise voltage range values are from $55.97 \mathrm{nV} / \sqrt{\mathrm{Hz}}$ to $44.06 \mathrm{nV} / \sqrt{\mathrm{Hz}}$ over the entire unity gain bandwidth $(\mathrm{GBW})$ values. Figure 9 depicts the equivalent input-referred noise (IRN) voltage simulation result of the circuit at $V_{D D}=\left|V_{S S}\right|=0.814 \mathrm{~V}$. The result shows that the achieved equivalent input-referred noise voltage range values are from $48.13 \mathrm{nV} / \sqrt{\mathrm{Hz}}$ to $44.75 \mathrm{nV} / \sqrt{\mathrm{Hz}}$ over the entire unity gain bandwidth (GBW) values. Consequently, the circuit has an excellent equivalent input-referred noise voltage performance specifications. 


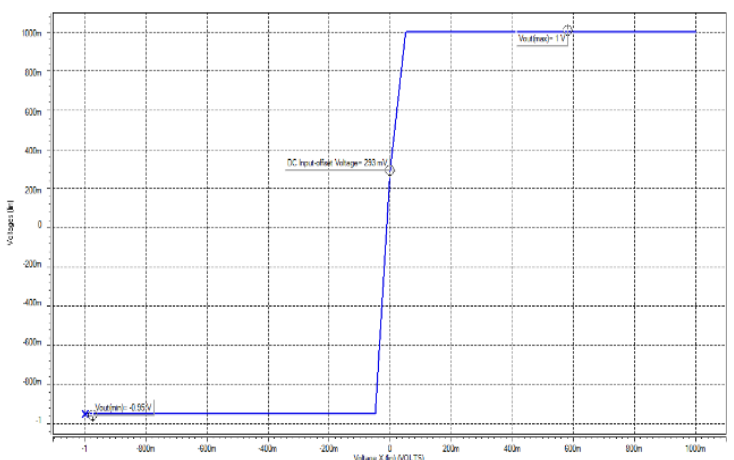

Figure 4. DC input-offset voltage $\left(V_{O S}\right)$ and output voltage swing of the circuit at $V_{D D}=\left|V_{S S}\right|=1 \mathrm{~V}$

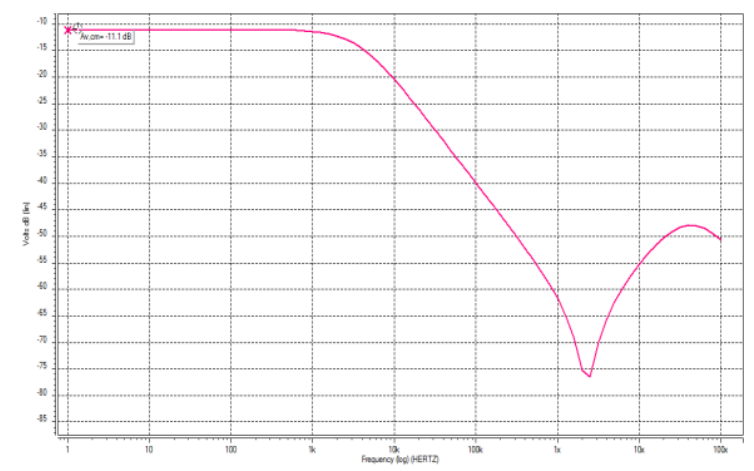

Figure 6. Common-mode voltage gain $\left(A_{v, \mathrm{~cm}}\right)$ of the circuit at $V_{D D}=\left|V_{S S}\right|=1 \mathrm{~V}$

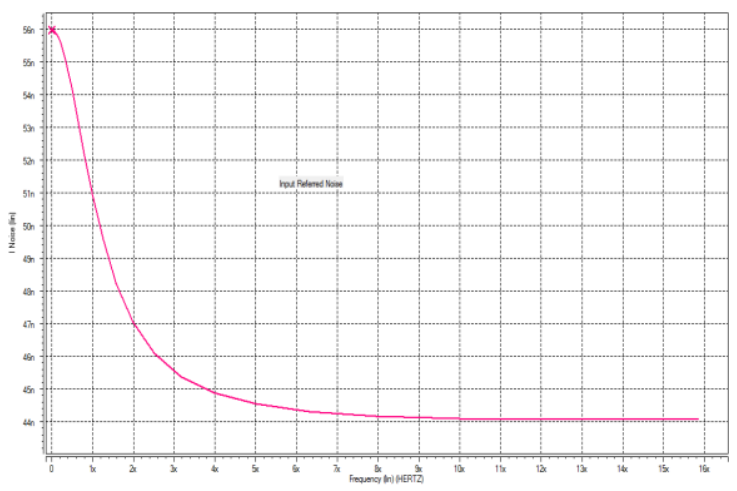

Figure 8. Equivalent input-referred noise voltage of the circuit at $V_{D D}=\left|V_{S S}\right|=1 \mathrm{~V}$

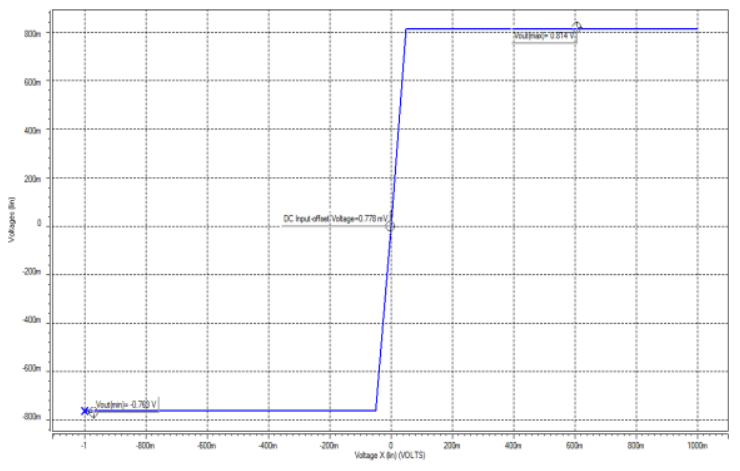

Figure 5. DC input-offset voltage $\left(V_{O S}\right)$ and output voltage swing of the circuit at $V_{D D}=\left|V_{S S}\right|=0.814 \mathrm{~V}$

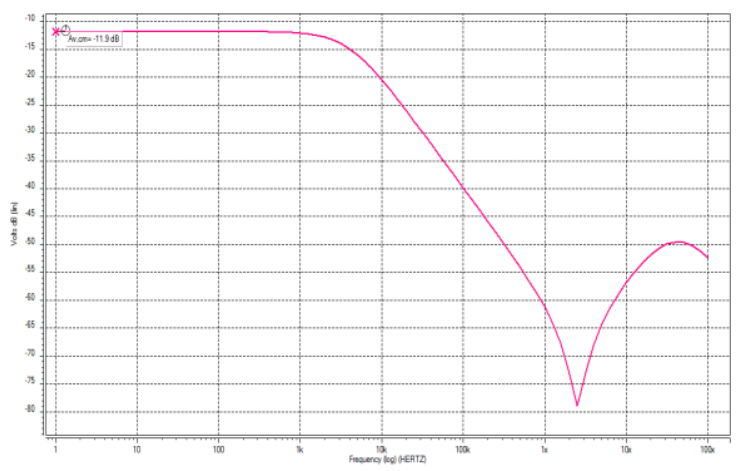

Figure 7. Common-mode voltage gain $\left(A_{v, \mathrm{~cm}}\right)$ of the circuit at $V_{D D}=\left|V_{S S}\right|=0.814 \mathrm{~V}$

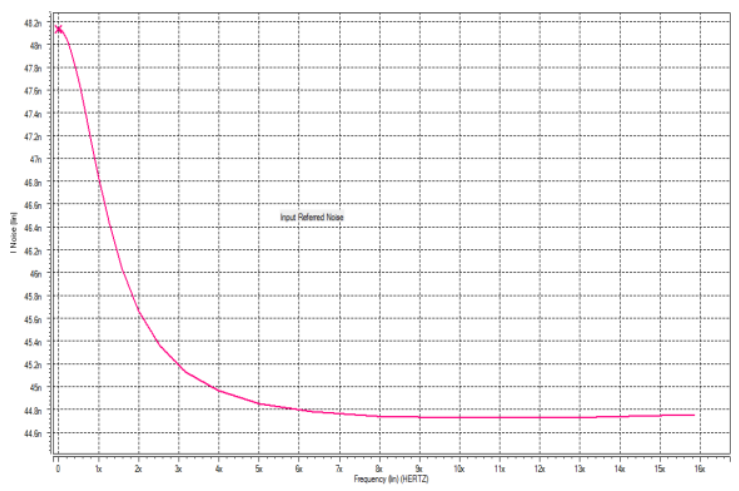

Figure 9. Equivalent input-referred noise voltage of the circuit at $V_{D D}=\left|V_{S S}\right|=0.814 \mathrm{~V}$

The HSPICE simulation results for the very LVs CMOS GD Op-Amp circuit in the unity-gain configuration determine the values of the following performance specifications: slew rates $\left(S R^{ \pm}\right)$, settling time $\left(T_{S}\right)$, input common-mode range (ICMR) voltage, and power-supply rejection ratios $\left(P S R R^{ \pm}\right)$. Figure 10 depicts the slew rates $\left(S R^{ \pm}\right)$and settling time $\left(T_{S}\right)$ simulation results of the circuit at $V_{D D}=\left|V_{S S}\right|=1 \mathrm{~V}$. The results show that the achieved positive slew rate value $\left(S R^{+}\right)$is $11.37 \mathrm{~V} / \mu \mathrm{s}$, and the negative slew rate value $\left(S R^{-}\right)$is $11.39 \mathrm{~V} / \mu \mathrm{s}$, while the settling time value $\left(T_{S}\right)$ is $137 \mathrm{~ns}$. Figure 11 depicts the slew rates $\left(S R^{ \pm}\right)$ and settling time $\left(T_{S}\right)$ simulation results of the circuit at $V_{D D}=\left|V_{S S}\right|=0.814 \mathrm{~V}$. The results show that the achieved positive slew rate value $\left(S R^{+}\right)$is $11.45 \mathrm{~V} / \mu \mathrm{s}$, and the negative slew rate value $\left(S R^{-}\right)$is $10.86 \mathrm{~V} / \mu \mathrm{s}$, while the settling time value $\left(T_{S}\right)$ is $86.2 \mathrm{~ns}$. Consequently, the circuit has high stability and fast settling time. 


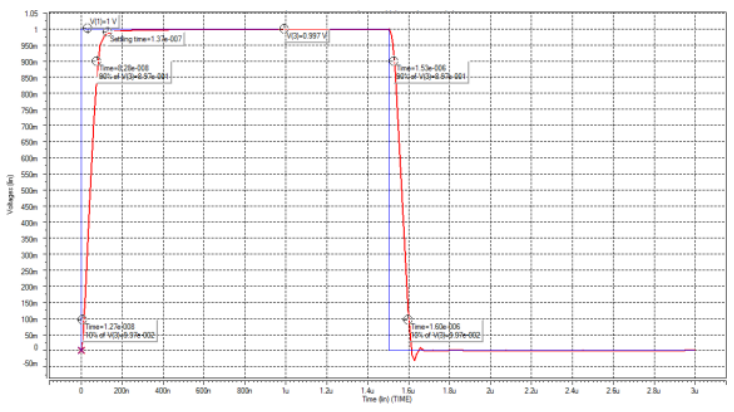

Figure 10. Slew rate $(\mathrm{SR})$ and settling time $\left(T_{S}\right)$ of the circuit at $V_{D D}=\left|V_{S S}\right|=1 \mathrm{~V}$

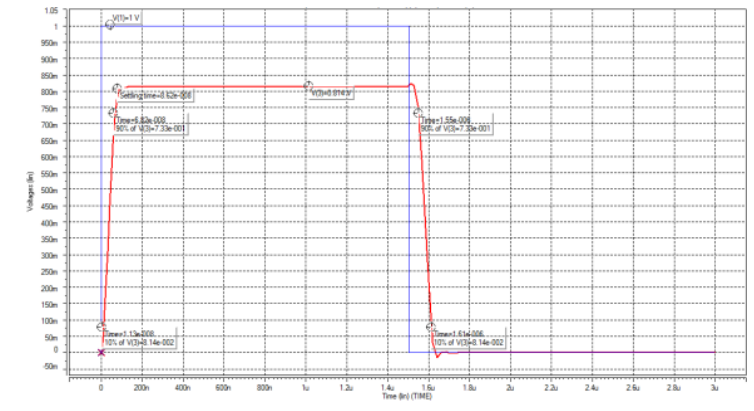

Figure 11. Slew rate $(\mathrm{SR})$ and settling time $\left(T_{S}\right)$ of the circuit at $V_{D D}=\left|V_{S S}\right|=0.814 \mathrm{~V}$

Figure 12 depicts the input common-mode range (ICMR) voltage simulation result of the circuit at $V_{D D}=\left|V_{S S}\right|=1 \mathrm{~V}$. The result shows that the achieved input common-mode range (ICMR) voltage value is from $V_{i n(\min )}=-0.484 \mathrm{~V}$ to $V_{i n(\max )}=1 \mathrm{~V}$. Figure 13 depicts the input common-mode range (ICMR) voltage simulation result of the circuit at $V_{D D}=\left|V_{S S}\right|=0.814 \mathrm{~V}$. The results show that the achieved input common-mode range (ICMR) voltage value is from $V_{i n(\min )}=-0.309 \mathrm{~V}$ to $V_{\text {in }(\max )}=0.814 \mathrm{~V}$.

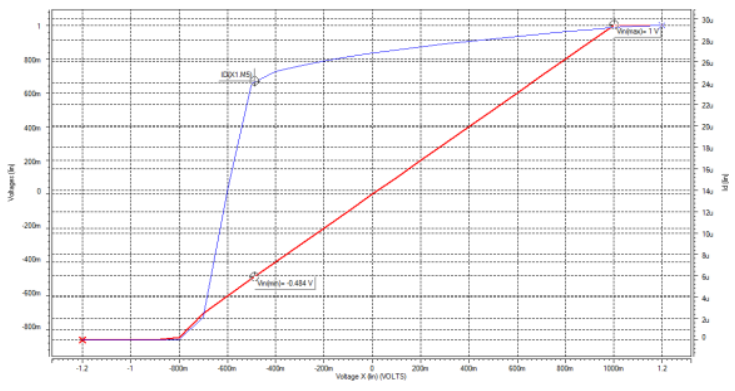

Figure 12. Input common-mode range (ICMR) voltage of the circuit at $V_{D D}=\left|V_{S S}\right|=1 \mathrm{~V}$

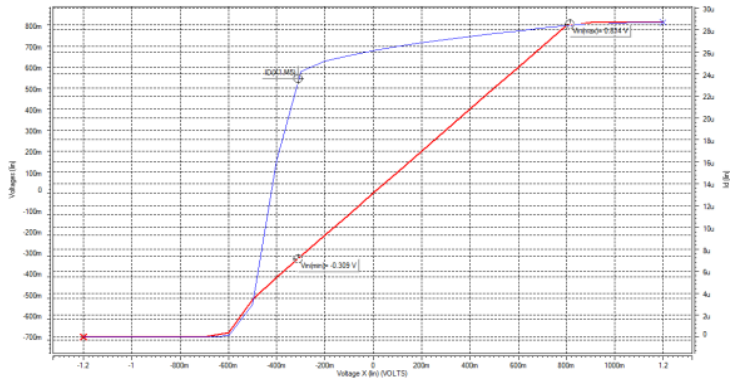

Figure 13. Input common-mode range (ICMR) voltage of the circuit at $V_{D D}=\left|V_{S S}\right|=0.814 \mathrm{~V}$

Figure 14 depicts the power-supply rejection ratios $\left(P S R R^{ \pm}\right)$simulation results of the circuit at $V_{D D}=$ $\left|V_{S S}\right|=1 \mathrm{~V}$. The results show that the achieved positive power-supply rejection ratio value $\left(P S R R^{+}\right)$is $74.2 \mathrm{~dB}$, and the negative power-supply rejection ratio value $\left(P S R R^{-}\right)$is $80.1 \mathrm{~dB}$. Figure 15 depicts the power-supply rejection ratios $\left(P S R R^{ \pm}\right)$simulation results of the circuit at $V_{D D}=\left|V_{S S}\right|=0.814 \mathrm{~V}$. The results show that the achieved positive power-supply rejection ratio value $\left(P S R R^{+}\right)$is $72.3 \mathrm{~dB}$, and the negative power-supply rejection ratio value $\left(P S R R^{-}\right)$ is $76.6 \mathrm{~dB}$. Consequently, the circuit has high rejections to the ripples from the power supplies voltages.

The performance specifications of the very LVs CMOS GD Op-Amp circuit at $V_{D D}=\left|V_{S S}\right|=1 \mathrm{~V}$ and $V_{D D}=\left|V_{S S}\right|=0.814 \mathrm{~V}$ are summarized in Table 3. It is evident from the listed simulation results in Table 3 that the values of total power dissipation $\left(P_{\text {diss }}\right)$, DC input-offset voltage $\left(V_{O S}\right)$, equivalent input-referred noise voltage, positive slew rate $\left(S R^{+}\right)$, and settling time $\left(T_{S}\right)$ are directly proportional to the power supplies' voltages values. Also, the values of overall gain $\left(A_{v}\right)$, output voltage swing range, common-mode rejection ratio (CMRR), negative slew rate value $\left(S R^{-}\right)$, input common-mode range voltage (ICMR), and powersupply rejection ratios $\left(P S R R^{ \pm}\right)$are inversely proportional to the power supplies' voltages values. Furthermore, the value of phase margin (PM) has not changed with the variation in the power supplies' voltages values. Consequently, the $P_{\text {diss }}$ value is improved by $19.8 \%$, the $V_{\text {OS }}$ value is improved by $99.7 \%$, the average value of the equivalent IRN voltage range is improved by $71.6 \%$, the $S R^{+}$value is improved by $0.7 \%$, and the $T_{S}$ value is improved by $37.1 \%$. Also, the $A_{v}$ value is decreased by $1.6 \%$, the average value of the output voltage swing range is decreased by $19.1 \%$, the CMRR value is decreased by $0.47 \%$, the $S R^{-}$ value is decreased by $4.6 \%$, the average value of ICMR voltage is decreased by $24.3 \%$, the $P S R R^{+}$value is decreased by $2.5 \%$, and the $P S R R^{-}$value is decreased by $4.3 \%$. Based on the preliminary results, it is evident that the very LVs CMOS GD Op-Amp circuit possesses high-performance specifications, and it has achieved the desired design performance specifications listed in Table 1 at the power supplies' voltages values $\pm 1 \mathrm{~V}$ and $\pm 0.814 \mathrm{~V}$. 
Furthermore, the comparisons of the performance specifications of the very LVs CMOS GD OpAmp circuit with the other Op-Amp circuits presented in the prior papers [11, 23, 25] are summarized in Table 4. It is evident from Table 4 that the very LVs CMOS GD Op-Amp circuit presented in this paper has better performance specifications values in terms of the overall gain $\left(A_{v}\right)$, unity gain bandwidth (GBW), output voltage swing which is approximately rail-to-rail swing, equivalent input-referred noise (IRN) voltage, settling time $\left(T_{S}\right)$, input common-mode range (ICMR) voltage, and power-supply rejection ratios $\left(P S R R^{ \pm}\right)$, whereas its main drawback is it has a higher total power dissipation $\left(P_{\text {diss }}\right)$ value.

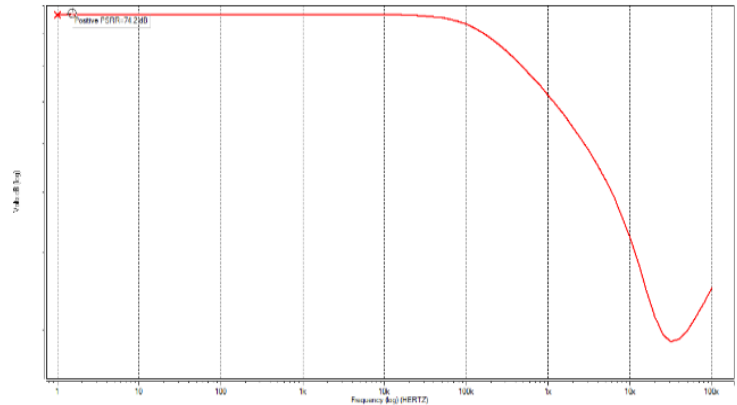

(a)

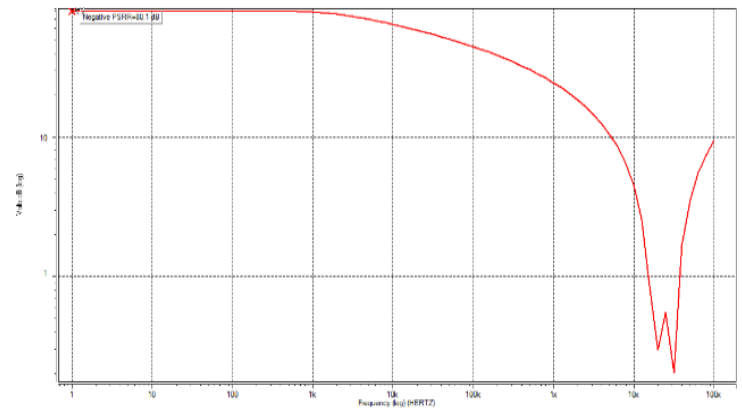

(b)

Figure 14. Power-supply rejection ratios $\left(P S R R^{ \pm}\right)$of the circuit at $V_{D D}=\left|V_{S S}\right|=1 \mathrm{~V}$, (a) magnitude of $P S R R^{+}$, (b) magnitude of $P S R R^{-}$

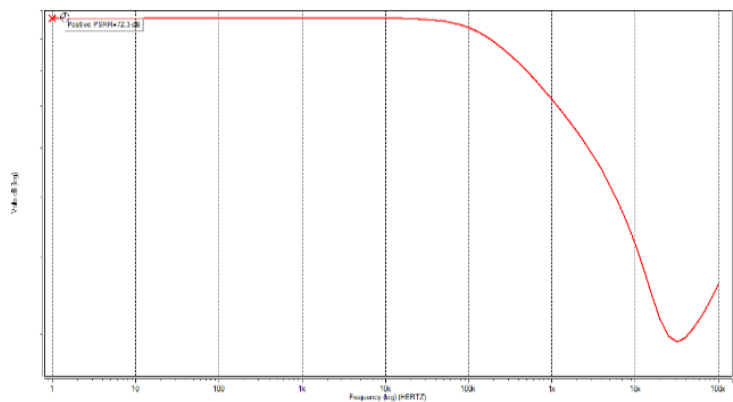

(a)

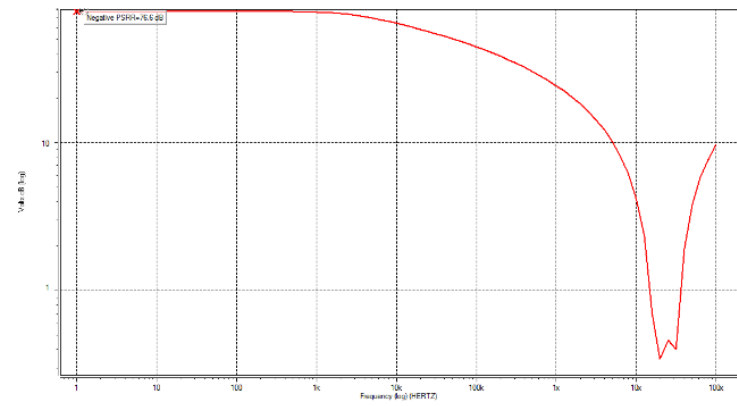

(b)

Figure 15 Power-supply rejection ratios $\left(P S R R^{ \pm}\right)$of the circuit at $V_{D D}=\left|V_{S S}\right|=0.814 \mathrm{~V}$, (a) magnitude of $P S R R^{+}$, (b) magnitude of $P S R R^{-}$

Table 3. Perfomance specifications summary of the very LVs CMOS GD Op-Amp circuit at $V_{D D}=$ $\left|V_{S S}\right|=1 \mathrm{~V}$ and at $V_{D D}=\left|V_{S S}\right|=0.814 \mathrm{~V}$

\begin{tabular}{|c|c|c|}
\hline Performance Specifications & Values at $V_{D D}=\left|V_{S S}\right|=1 \mathrm{~V}$ & Values at $V_{D D}=\left|V_{S S}\right|=0.814 \mathrm{~V}$ \\
\hline Overall Gain $\left(A_{v}\right)(\mathrm{dB})$ & 73.1 & 71.9 \\
\hline Unity Gain Bandwidth (GBW) (MHz) & 14.9 & 14.4 \\
\hline Phase Margin $(\mathrm{PM})\left(^{\circ}\right)$ & 61 & 61 \\
\hline Power Dissipation $\left(P_{\text {diss }}\right)(\mathrm{mW})$ & 0.91 & 0.73 \\
\hline Input Resistance $\left(R_{\text {in }}\right)(\mathrm{M} \Omega)$ & 387 & 411 \\
\hline Output Resistance $\left(R_{\text {out }}\right)(\mathrm{K} \Omega)$ & 14.8 & 13.9 \\
\hline DC Input-offset Voltage $\left(V_{O S}\right)(\mathrm{mV})$ & 293 & 0.778 \\
\hline Output Voltage Swing (V) & -0.95 to 1 & -0.763 to 0.814 \\
\hline $\operatorname{CMRR}(\mathrm{dB})$ & 84.2 & 83.8 \\
\hline Eq. IRN voltage $(\mathrm{nV} / \sqrt{\mathrm{Hz}})$ & 55.97 to 44.06 & 48.13 to 44.75 \\
\hline Slew Rate $(+v e)(V / \mu s)$ & 11.37 & 11.45 \\
\hline Slew Rate (-ve) $(V / \mu s)$ & 11.39 & 10.86 \\
\hline Settling Time $\left(T_{S}\right)(\mathrm{ns})$ & 137 & 86.2 \\
\hline$V_{i n(\min )}(\mathrm{V})$ & -0.484 & -0.309 \\
\hline$V_{\text {in }(\max )}(\mathrm{V})$ & 1 & 0.814 \\
\hline $\operatorname{PSRR}^{+}(\mathrm{dB})$ & 74.2 & 72.3 \\
\hline$P S R R^{-}(\mathrm{dB})$ & 80.1 & 76.6 \\
\hline Load Capacitance $\left(C_{L}\right)(\mathrm{pF})$ & 10 & 10 \\
\hline Resistance $\left(R_{1}\right)(\mathrm{K} \Omega)$ & 12.3 & 12.3 \\
\hline
\end{tabular}


Table 4. Performance specifications comparisons of the Op-Amp circuits

\begin{tabular}{|c|c|c|c|c|}
\hline Performance Specifications & This paper & [11] & [23] & [25] \\
\hline CMOS Technology (nm) & 90 & 180 & 500 & 350 \\
\hline Power Supply Voltage (V) & \pm 1 & 1.8 & \pm 1 & \pm 2 \\
\hline Overall Gain $\left(A_{v}\right)(\mathrm{dB})$ & 73.1 & 72.04 & 61.5 & 72 \\
\hline Unity Gain Bandwidth (GBW) (MHz) & 14.9 & 13.33 & 2.31 & 12.64 \\
\hline Phase Margin $(\mathrm{PM})\left(^{\circ}\right)$ & 61 & 62.46 & 89 & 65.8 \\
\hline Power Dissipation $\left(P_{\text {diss }}\right)(\mathrm{mW})$ & 0.91 & 0.13 & 0.24 & - \\
\hline Output Voltage Swing (V) & -0.95 to 1 & - & - & 0.1106 to 1.996 \\
\hline CMRR $(\mathrm{dB})$ & 84.2 & - & 90 & - \\
\hline Eq. IRN voltage $(\mathrm{nV} / \sqrt{\mathrm{Hz}})$ & $50.94 @ 1 \mathrm{MHz}$ & - & $93 @ 1 \mathrm{MHz}$ & - \\
\hline Slew Rate $(+v e)(V / \mu s)$ & 11.37 & 11.63 & 3.4 & 20 \\
\hline Slew Rate $(-v e)(V / \mu s)$ & 11.39 & - & - & - \\
\hline Settling Time $\left(T_{S}\right)(\mathrm{ns})$ & 137 & - & - & - \\
\hline$V_{\text {in }(\min )}(\mathrm{V})$ & -0.484 & - & - & 0.509 \\
\hline$V_{i n(\max )}(\mathrm{V})$ & 1 & - & - & 1.511 \\
\hline$P S R R^{+}(\mathrm{dB})$ & 74.2 & 72.09 & 51 & - \\
\hline$P_{S R R^{-}}(\mathrm{dB})$ & 80.1 & - & 50 & - \\
\hline Load Capacitance $\left(C_{L}\right)(\mathrm{pF})$ & 10 & 2 & 25 & 11.5 \\
\hline
\end{tabular}

\section{CONCLUSION AND FUTURE WORK}

In this paper, a simple and very LVs CMOS GD Op-Amp circuit has been designed by using 90nm CMOS technology process parameters. The folded cascode (FC) technique is used in the differential input stage to meet the requirement of operation under the conditions of very LVs power supplies. The achieved HSPICE-based simulation results at $\pm 1 \mathrm{~V}$ and $\pm 0.814 \mathrm{~V}$ power supplies' voltages demonstrate the validity of the designed very LVs CMOS GD Op-Amp circuit operation with high-performance specifications. Consequently, the very LVs CMOS GD Op-Amp circuit is very suitable for growing global electronics markets' needs for very LVs submicron and nanometer VLSI analog and mixed-signal systems.

In the future, the work should focus on minimizing further the positive and negative power supply voltages values $\left(V_{D D}, V_{S S}\right.$, respectively) by reducing the threshold voltages values $\left(V_{t h, n, p}\right)$ through the use of differential BD nMOSFET transistors pair M1 and M2 and the use of balanced BD pMOSFET active current source loads transistors M3 and M4 in the differential input stage. Thus, allowing the designed very LVs CMOS GD Op-Amp circuit in this paper to operate in the range of ultra low voltage (ULV) power supplies. Furthermore, using a suitable DC level-shifters MOSFETs technique can maximize further the values of ICMR voltages without the need to increase the complexity of the designed very LVs CMOS GD Op-Amp circuit. Finally, the total power dissipation $\left(P_{\text {diss }}\right)$ value of the designed very LVs CMOS GD Op-Amp circuit can be minimized further through the use of MOSFET transistor to achieve proper gate-source biasing voltages $\left(V_{G S}\right)$ of pMOSFET transistors M6 and M7 instead of using the resistor $R_{1}$.

\section{REFERENCES}

[1] A. J. Lopez-Martin, S. Baswa, J. Ramirez-Angulo and R. G. Carvajal, "Low-Voltage Super Class AB CMOS OTA Cells with Very High Slew Rate and Power Efficiency," IEEE Journal of Solid-State Circuits, vol. 40, no. 5, pp. 1068-1077, 2005.

[2] K. J. Raut, R. V. Kshirsagar and A. C. Bhagali, "Low-Voltage High-Gain Folded Architecture Operational Amplifier," in 2016 Conference on Advances in Signal Processing (CASP), Pune, 2016, pp. 160-163.

[3] W. M. E. A. bin Wan, S. H. Ruslan, N. Ahmad, W. M. Jubadi and R. Sanudin, "Comparative Study of Symmetrical OTA Performance in $180 \mathrm{~nm}, 130 \mathrm{~nm}$ and $90 \mathrm{~nm}$ CMOS Technology," Indonesian Journal of Electrical Engineering and Computer Science (IJEECS), vol. 14, no. 1, pp. 230-240, 2019.

[4] H. Veldandi and R. A. Shaik, "Low-Voltage PVT-Insensitive Bulk-Driven OTA with Enhanced DC Gain in 65-nm CMOS Process," AEU-International Journal of Electronics and Communications, vol. 90, pp. 88-96, 2018.

[5] K. J. De Langen and J. H. Huijsing, "Compact Low-Voltage Power-Efficient Operational Amplifier Cells for VLSI," IEEE Journal of Solid-State Circuits, vol. 33, no.10, pp. 1482-1496, 1998.

[6] V. Bendre and A. K. Kureshi, "Performance Analysis of Operational Transconductance Amplifier at 180nm Technology," in 2016 Second International Innovative Applications of Computational Intelligence on Power, Energy and Controls with their Impact on Humanity (CIPECH), Ghaziabad, pp. 271-276, 2016.

[7] A. P. Kumar, B. L. V. S. S. Aditya, G. Sony, Ch. Prasanna and A. Satish, "Estimation of Power and Delay in CMOS Circuits using LCT," Indonesian Journal of Electrical Engineering and Computer Science (IJEECS), vol. 14, no. 2, pp. 990-998, 2019.

[8] N. F. Kosmani, F. A. Hamid and M. A. Razali, "A Comparison of Performance between Double-Gate and Gate-allaround Nanowire MOSFET," Indonesian Journal of Electrical Engineering and Computer Science (IJEECS), vol. 13, no. 2, pp. 801-807, 2019.

[9] A. Rjoub, M. Mistarihi and N. Al Taradeh, "Accurate Leakage Current Models for MOSFET Nanoscale Devices," International Journal of Electrical and Computer Engineering (IJECE), vol. 10, no. 3, pp. 2313-2321, 2020. 
[10] B. Wen, Q. Zhang, X. Zhao, X. Lv and Y. Wang, "Trade-offs Among Power Consumption and other Design Parameters of Two-Stage Recycling Folded Cascode OTA that using Embedded Cascode Current Buffer Compensation Technology," Integration, vol. 68, pp. 62-70, 2019.

[11] H. Gupta, G. K. Mishra, N. Z. Rizvi and S. K. Patnaik, "Design of High PSRR Folded Cascode Operational Amplifier for LDO Applications," in 2016 International Conference on Electrical, Electronics, and Optimization Techniques (ICEEOT), Chennai, pp. 4617-4621, 2016.

[12] W. M. E. A. W. Jusoh and S. H. Ruslan, "Design and Analysis of Current Mirror OTA in $45 \mathrm{~nm}$ and $90 \mathrm{~nm}$ CMOS Technology for Bio-Medical Application," Bulletin of Electrical Engineering and Informatics (BEEI), vol. 9, no. 1, pp. 221-228, 2020.

[13] M. Kaur and J. Kaur, "Iddq Testing of Low Voltage CMOS Operational Transconductance Amplifier," International Journal of Electrical and Computer Engineering (IJECE), vol. 8, no. 3, pp. 1467-1477, 2018.

[14] H. D. Rico-Aniles, J. Ramirez-Angulo, A. J. Lopez-Martin and R. G. Carvajal, "360nW Gate-Driven Ultra-Low Voltage CMOS Linear Transconductor with $1 \mathrm{MHz}$ Bandwidth and Wide Input Range," IEEE Transactions on Circuits and Systems II: Express Briefs, pp. 1-1, 2020.

[15] V. Ceperic, Z. Butkovic and A. Baric, "Design and Optimization of Self-Biased Complementary Folded Cascode," in MELECON 2006-2006 IEEE Mediterranean Electrotechnical Conference, Malaga, pp. 145-148, 2006.

[16] L. L. Malavolta, R. L. Moreno and T. C. Pimenta, "A Self-Biased Operational Amplifier of Constant gm for 1.5 V Rail-toRail Operation in 130nm CMOS," in 2016 28th International Conference on Microelectronics (ICM), Giza, pp. 45-48, 2016.

[17] S. S. Rajput and S. S. Jamuar, "Low Voltage Analog Circuit Design Techniques," IEEE Circuits and Systems Magazine, vol. 2, no. 1, pp. 24-42, 2002.

[18] F. Khateb, S. B. Dabbous and S. Vlassis, "A Survey of Non-Conventional Techniques for Low-Voltage Low-Power Analog Circuit Design," Radioengineering, vol. 22, no. 2, pp. 415-427, 2013.

[19] M. Rakús, V. Stopjaková and D. Arbet, "Design Techniques for Low-Voltage Analog Integrated Circuits," Journal of Electrical Engineering, vol. 68, no. 4, pp. 245-255, 2017.

[20] A. J. Lopez-Martin, M. P. Garde, J. M. Algueta, C. A. de la Cruz Blas, R. G. Carvajal and J. Ramirez-Angulo, "Enhanced Single-Stage Folded Cascode OTA Suitable for Large Capacitive Loads," IEEE Transactions on Circuits and Systems II: Express Briefs, vol. 65, no. 4, pp. 441-445, 2018.

[21] U. Bansal and M. Gupta, "Two Stage Class AB-AB Amplifier using FGMOS for Low Voltage Operation and SSF for Frequency Compensation," AEU-International Journal of Electronics and Communications, vol. 73, pp. 59-67, 2017.

[22] C. A. De La Cruz-Blas, M. P. Garde and A. Lopez-Martin, "Super Class AB Transconductor with Slew-Rate Enhancement using QFG MOS Techniques," in 2017 European Conference on Circuit Theory and Design (ECCTD), Catania, pp. 1-4, 2017.

[23] M. P. Garde, A. Lopez-Martin, J. M. Algueta, R. G. Carvajal and J. Ramirez-Angulo, "Class AB Amplifier with Enhanced Slew Rate and GBW," International Journal of Circuit Theory and Applications, vol. 47, no. 8, pp. 1199-1210, 2019.

[24] P. E. Allen and D. R. Holberg, "CMOS Analog Circuit Design," Third Edition, Oxford University Press, New York, 2012.

[25] K. B. Maji, R. Kar, D. Mandal, B. Prasanthi and S. P. Ghoshal, "Design of Low-Voltage CMOS Op-Amp using Evolutionary Optimization Techniques," in Advances in computer communication and computational sciences. Advances in Intelligent Systems and Computing, vol. 759, pp. 257-267, 2018.

\section{BIOGRAPHIES OF AUTHOR}
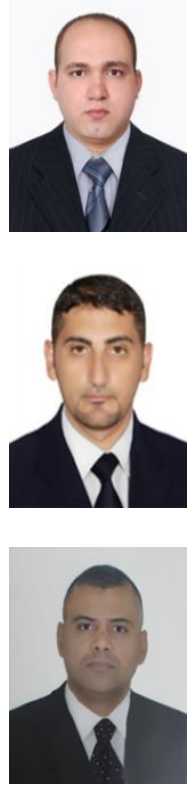

Hayder Khaleel AL-Qaysi received a bachelor's degree in electronic engineering from College of Engineering, University of Diyala, Iraq in 2004 and received a master's degree in electronic and communication engineering from Yildiz Technical University, Turkey, in 2017. Area of research interests in the electronic circuits design, signal processing, semiconductor technology, and VLSI analog and mixed-signal systems design. He is currently work as an assistant lecturer at College of Engineering, University of Diyala, Iraq. He has 2 published papers.

Musaab Mohammed Jasim received a bachelor's degree in computer engineering from College of Engineering, University of Diyala, Iraq, in 2007 and received a master's degree in computer engineering from Yildiz Technical University, Turkey in 2017. Area of research interests in the computer networks, signal processing, and image processing. He is currently work as an assistant lecturer at College of Engineering, University of Diyala, Iraq. He has 1 published paper.

Siraj Manhal Hameed was born in Diyala, Iraq, in 1981, received his B.Sc from University of Diyala Iraq in 2004, MSc from University of Technology Baghdad Iraq in 2014. He is currently assistant lecturer at the Department of computer Engineering, College of Engineering, University of Diyala Iraq. His current research interests are power system modeling, renewable energy, Electrical drives. He is teaching several basic subjects of the computer engineering, University of Diyala, Iraq. He has 3 published papers. 